\title{
Determination of Norfloxacin and Ciprofloxacin in Chicken Meat Based on Matrix Solid-Phase Dispersion Extraction and Capillary Zone Electrophoresis
}

\author{
Shihao Zhao, ${ }^{1}$ Hongru Zhao, ${ }^{2}$ Hai Zhu, ${ }^{3}$ Chengyao Li, ${ }^{4}$ Xinli Lu, ${ }^{2}$ and Siyuan $\mathrm{Bi}^{3,4}$ \\ ${ }^{1}$ College of Biology Science and Engineering, Hebei University of Economics and Business, Shijiazhuang 050000, China \\ ${ }^{2}$ Institute of STD/AIDS Prevention and Control, Hebei Center for Disease Prevention and Control, Shijiazhuang 050000, China \\ ${ }^{3}$ Shenzhen Bioeasy Biotechnologies Co., Ltd., Shenzhen 518102, China \\ ${ }^{4}$ Department of Transfusion Medicine, Southern Medical University, Guangzhou 510515, China
}

Correspondence should be addressed to Xinli Lu; lxlii2015@163.com and Siyuan Bi; bisiyuan0129@126.com

Received 26 February 2014; Revised 23 April 2014; Accepted 24 April 2014; Published 7 May 2014

Academic Editor: Alexandre Giuliani

Copyright (C) 2014 Shihao Zhao et al. This is an open access article distributed under the Creative Commons Attribution License, which permits unrestricted use, distribution, and reproduction in any medium, provided the original work is properly cited.

\begin{abstract}
This study describes an effective matrix solid-phase dispersion (MSPD) extraction method for determining norfloxacin (NOR) and ciprofloxacin (CIP) in chicken meat by capillary zone electrophoresis (CZE). The optimum conditions for separating NOR and CIP were as follows: $60 \mathrm{~cm} \times 75 \mu \mathrm{m}$ i.d. capillary, $40 \mathrm{mmol} \mathrm{L}^{-1}$ borate buffer solution $(\mathrm{pH} 8.5)$, separation voltage at $16 \mathrm{kV}$, and detection wavelength at $280 \mathrm{~nm}$. Before CZE determination, the chicken meat samples were purified and enriched by using an MSPD extraction step with a preconditioned $\mathrm{C}_{18}$ cartridge and by eluting the compound with $3.0 \mathrm{~mL}$ of acetonitrile. A good linear fit curve with the concentration range of $0.10 \mu \mathrm{g} \mathrm{g}^{-1}$ to $500 \mu \mathrm{g} \mathrm{g}^{-1}$ for NOR and CIP was obtained, with regression coefficients of 0.9994 and 0.9986 , respectively. The limits of detection of NOR and CIP were 0.04 and $0.03 \mu \mathrm{g} \mathrm{g}^{-1}$, respectively. The proposed method was successfully applied to determine NOR and CIP in chicken meat.
\end{abstract}

\section{Introduction}

Fluoroquinolones (FQs) are a class of relatively new and entirely man-made, nonsteroidal antibiotics/antibacterials [1]. The FQ norfloxacin (NOR) is the first-choice drug for the treatment of diseases caused by Campylobacter, Escherichia coli, Shigella, and Vibrio cholerae. NOR is used to treat gonorrhea, eye infection, and urinary tract infection [24]. The FQ ciprofloxacin (CIP) is used to treat systemic infections, including urinary tract, respiratory, gastrointestinal, and cutaneous infections. CIP affects the growth and reproduction of bacteria by inhibiting a subunit of bacterial DNA gyrase and an essential enzyme that maintains the super helical twists in the bacterial DNA [5]. These quinolones and antibiotics are generally used for the prophylaxis and treatment of diseases; they are also used as feed additives for mass gain promotion [6]. The widespread use of FQs presents potential hazards to human health, such as the emergence and spread of drug-resistant bacterial strains and the possible induction of cancer [7]. Concerns about drug residues entering the food chain and contributing to bacterial resistance have prompted the European Union and China to establish maximum residue levels (MRLs) for various classes of antibiotics, including FQs, in matrices of food originating from animals of various species [8].

Several methods for the determination of NOR and CIP have been reported in recent years. These methods include high-performance liquid chromatography (HPLC) [9], flow-injection chemiluminescence (CL) [10], electrochemical method [11], and spectrophotometric method [12]. However, the application of HPLC is limited by its complicated system and maintenance, large sample requirement, and expensive reagents. CL and spectrophotometric method cannot be used to determine FQs in complex biological samples because they both lack separation capacity. Capillary electrophoresis (CE) has attracted considerable attention in 
recent years for the quantitative analysis of biological samples $[13,14]$ because of its simplicity, high efficiency, minimum solvent and sample requirements, and relatively low cost.

A preliminary extraction step by liquid-liquid extraction (LLE) [15] or solid-phase extraction (SPE) [16] was previously employed to clean the sample in preparation for further analysis. These processes are complicated, time consuming and need large amounts of organic solvent. Matrix solidphase dispersion (MSPD) is based on SPE in which a homogeneous dispersion of the matrix is mixed with a suitable solid adsorbent (silicagel, diatomaceous earth, alumina, $\mathrm{C}_{18}$, etc.). This method has been successfully applied to extract target analytes from biological samples; compared with other processes, MSPD requires shorter analytical time, smaller sample size, and lower solvent consumption $[17,18]$.

This study describes a comprehensive capillary zone electrophoresis (CZE) method for the simultaneous determination of NOR and CIP residues in chicken meat. MSPD was used to extract NOR and CIP from chicken meat. Method development efforts were focused on the optimization of the MSPD, the cleanup procedure, and the avoidance of contamination. In addition, parameters affecting the separation efficiency of CZE were optimized. Finally, the developed method was validated for the analysis of NOR and CIP in real samples with better results.

\section{Experimental}

2.1. Chemical and Reagents. NOR and CIP were purchased from the National Institute for Food and Drug Control (Beijing, China). Analytical reagent-grade methanol, toluene, chloroform, and acetonitrile were obtained from Beijing Chemical Factory (Beijing, China). Boric acid $\left(\mathrm{H}_{3} \mathrm{BO}_{3}\right)$ and sodium hydroxide $(\mathrm{NaOH})$ were purchased from Tianjin General Chemical Reagent Factory (Tianjin, China). Diatomaceous earth (Florisil, $200 \mathrm{mesh}$ ) and silica (200 mesh) were obtained from the Chinese Medical and Biological Products Institute (Beijing, China). YWG- $\mathrm{C}_{18^{-}}$ $\left(\mathrm{C}_{18^{-}}\right)$and YWG-C $8^{-}\left(\mathrm{C}_{8^{-}}\right)$bonded silica materials (surface area $300 \mathrm{~m}^{2} \mathrm{~g}^{-1}$, average pore size: $10 \mu \mathrm{m}$ ) were obtained from Zhongkeantai Tech Co., Ltd. (Lanzhou, China). Florisil, silica, $\mathrm{C}_{18}$, and $\mathrm{C}_{8}$ were baked at $650^{\circ} \mathrm{C}$ for $5 \mathrm{~h}$, dried overnight at $100^{\circ} \mathrm{C}$ for $2 \mathrm{~h}$, and then stored in a desiccator for future use. Borate buffer ionic strength calculations were performed using the HP 3D CE Buffer Calculator version 1.00 (Hewlett-Packard Corp., USA). Aqueous solutions of carrier electrolytes and of standards were prepared by using 18.2 $\mathrm{M} \Omega \cdot \mathrm{cm}$ water from a Milli-Q water purification system (Millipore, Bedford, MA, USA) and were filtered through a $0.22 \mu \mathrm{m}$ membrane before use.

2.2. Procedure of MSPD. The working procedure of MSPD was the same as [19]. Approximately $0.02 \mathrm{~g}$ of chicken meat was homogenized in $2 \mathrm{~mL}$ of sodium chloride $\left(1 \mathrm{~mol} \mathrm{~L}^{-1}\right)$, transferred into a glass mortar, and then soaked in a suitable amount of standard solution. After $10 \mathrm{~min}, 1.0 \mathrm{~g}$ of $\mathrm{C}_{18}$ (dispersion adsorbent) was mixed with the sample. The homogeneous mixture was loaded into a cartridge, which
TABLE 1: The effects of different adsorbents on recoveries of NOR and CIP $(n=3)$.

\begin{tabular}{lcccc}
\hline \multirow{2}{*}{ Absorbent } & \multicolumn{2}{c}{ NOR } & \multicolumn{2}{c}{ CIP } \\
& Recovery (\%) & RSD (\%) & Recovery (\%) & RSD (\%) \\
\hline Florisil & 62.4 & 3.9 & 63.6 & 5.6 \\
Silica & 35.4 & 6.8 & 28.4 & 8.4 \\
$\mathrm{C}_{8}$ & 79.4 & 4.5 & 72.6 & 3.6 \\
$\mathrm{C}_{18}$ & 85.6 & 4.3 & 89.2 & 3.8 \\
\hline
\end{tabular}

was prepacked with $0.2 \mathrm{~g}$ of $\mathrm{C}_{18}$ particles. The cartridge was rinsed with $3.0 \mathrm{~mL}$ of methanol- $\mathrm{H}_{2} \mathrm{O}(1: 19, \mathrm{v} / \mathrm{v})$ and eluted with $3.0 \mathrm{~mL}$ of acetonitrile. The eluates were evaporated to dryness at $50^{\circ} \mathrm{C}$ under a gentle stream of nitrogen gas. The dry residues were reconstituted in $200 \mu \mathrm{L}$ of background electrolyte (BGE) and then vortex-mixed for $20 \mathrm{~s}$ for $\mathrm{CE}$ analysis.

2.3. CE Analysis. CE analysis was performed on a Beckman Coulter Proteome Lab PA800 (Beckman Coulter, Inc., Fullerton, CA, USA) instrument equipped with an ultraviolet (UV) detector and operated in normal polarity mode. Data acquisition and instrument control were carried out using 32 Karat software 8.0 (Beckman Coulter, Inc., Fullerton, CA, USA). An untreated fused-silica capillary of $60 \mathrm{~cm} \times$ $75 \mu \mathrm{m}$ i.d., $40 \mathrm{~cm}$ from inlet to detector, was used for the determinations. The capillary was activated daily by rinsing it with $0.1 \mathrm{~mol} \mathrm{~L}^{-1}$ of $\mathrm{NaOH}$ for $30 \mathrm{~min}$, with Milli-Q water for $30 \mathrm{~min}$, and then with running buffer for $30 \mathrm{~min}$. A $40 \mathrm{mmol} \mathrm{L}^{-1}$ boric acid solution adjusted with $\mathrm{NaOH}$ to $\mathrm{pH}$ 8.5 was used as the BGE. Separation was carried out by applying a voltage of $16 \mathrm{kV}$. The temperature of the capillary cartridge was maintained at $25^{\circ} \mathrm{C}$ by a liquid cooling system. The injection was hydrodynamic at a pressure of 1.0 psi for $2 \mathrm{~s}$. Detection was performed by a UV detector at $280 \mathrm{~nm}$.

\section{Results and Discussion}

3.1. Optimization of the MSPD Procedure. $10.00 \mu \mathrm{gg}^{-1}$ of NOR and CIP in drug-free chicken meat were added into a homogeneous mixture before extraction to investigate in detail the effects of the main factors in MSPD on recovery. Four MSPD adsorbents ( $1 \mathrm{~g}$ ), namely, Florisil, silica, $\mathrm{C}_{8}$, and $\mathrm{C}_{18}$, were examined. The results are given in Table 1. Comparison of the behaviour of these four adsorbents reveals that $\mathrm{C}_{18}$ provided an overall comparable efficiency, significantly better than that of silica, Florisil, and $\mathrm{C}_{8} \cdot \mathrm{C}_{18}$ polarity was similar to the target analytes. The recoveries of two analytes $(85.6 \%$ and $89.2 \%$ ) were the highest when $\mathrm{C}_{18}$ was used as dispersion adsorbent. When the other adsorbents were used, the two analytes had lower recoveries and more peaks interfering with analyte detection. Therefore, $\mathrm{C}_{18}$ was chosen as the optimum dispersion adsorbent.

Since the MSPD is a complex process and according to the character of the sample (polarity, solubility, pKa, etc.), the washing and elution solvent should be carefully chosen. A 


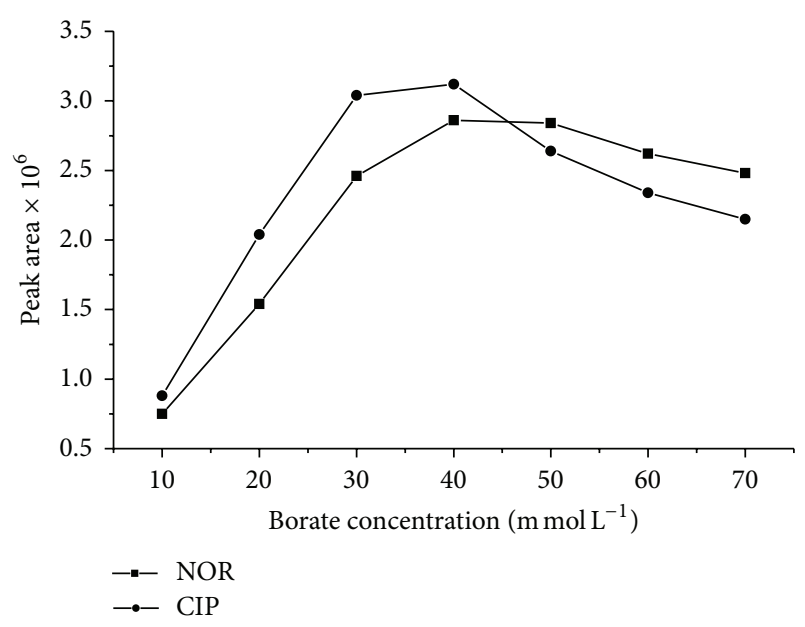

FIGURE 1: Effects of borate concentration on CZE performance.

washing step in MSPD was investigated using toluene, chloroform, methanol, and water as potential washing solvents to enhance the selectivity of MSPD and to decrease the crossreactivity. The best results were obtained when methanol$\mathrm{H}_{2} \mathrm{O}(1: 19, \mathrm{v} / \mathrm{v})$ was used as the washing solvent. Interferences from endogenic components were observed when the volume of methanol- $\mathrm{H}_{2} \mathrm{O}$ was lower than $3.0 \mathrm{~mL}$. However, the recovery decreased when the volume of methanol- $\mathrm{H}_{2} \mathrm{O}$ was higher than $3.0 \mathrm{~mL}$. Therefore, $3.0 \mathrm{~mL}$ of methanol- $\mathrm{H}_{2} \mathrm{O}$ $(1: 19, \mathrm{v} / \mathrm{v})$ was used. In addition, elution solutions such as water, methanol, and acetonitrile were investigated. The best recoveries of NOR and CIP were obtained using $3.0 \mathrm{~mL}$ of acetonitrile as elution solution.

3.2. Optimization of CZE. Electrolyte concentration has a significant effect on the separation performance because it can influence the Joule heating, the electroosmotic flow (EOF), ionic strength, viscosity of electrolyte, and the current produced in the capillary. Therefore, the electrolyte concentration would affect the migration time and peak area. The effect of different borate concentrations $\left(10 \mathrm{mmol} \mathrm{L}^{-1}\right.$ to $70 \mathrm{mmol} \mathrm{L}^{-1}$ ) in BGE was studied (Figure 1). The $\mathrm{pH}$ was adjusted to 8.5 , and the concentration of the two analytes was fixed at $10.0 \mu \mathrm{gg}^{-1}$. The peak area of the analytes gradually increased when the concentration of borate changed from $10 \mathrm{mmol} \mathrm{L}^{-1}$ to $40 \mathrm{mmol} \mathrm{L}^{-1}$. The peak area decreased and the analysis time increased significantly when the borate concentration was higher than $40 \mathrm{mmol} \mathrm{L}^{-1}$, and migration time was prolonged. Therefore, the best borate concentration was $40 \mathrm{mmol} \mathrm{L}^{-1}$.

Because NOR ( $\mathrm{pK}_{\mathrm{a} 1}$ 6.1, $\mathrm{pK}_{\mathrm{a} 2}$ 8.5) and CIP $\left(\mathrm{pK}_{\mathrm{a} 1}\right.$ 6.1, $\mathrm{pK}_{\mathrm{a} 2}$ 8.7) are zwitterionic compounds [20], buffer $\mathrm{pH}$ not only affects the EOF, but also affects the existence form of the two analytes. The effect of buffer $\mathrm{pH}$ on the separation of the two analytes was studied (Figure 2). The concentration of borate was $40 \mathrm{mmol} \mathrm{L}^{-1}$, and the concentration of the two analytes was fixed at $10.0 \mu \mathrm{g} \mathrm{g}^{-1}$. The result demonstrated that the peak area increased as the $\mathrm{pH}$ of BGE increased from

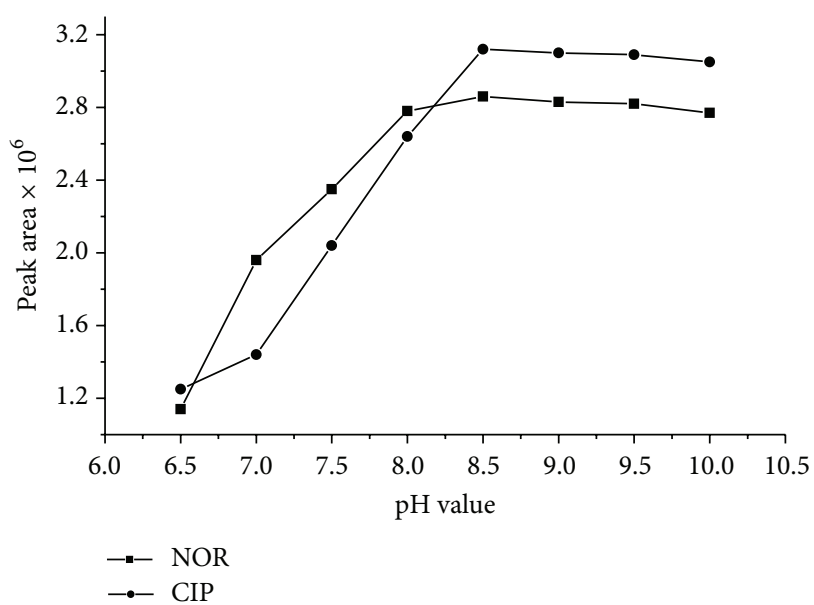

FIGURE 2: Effects of $\mathrm{pH}$ values on CZE performance.

6.5 to 8.5. However, the peak area was almost constant, but the migration time was prolonged when the $\mathrm{pH}$ was more than 8.5. This is due to the analytes existing in the form of anions: when the $\mathrm{pH}$ was higher than 8.5 , they have the biggest absorbance at $280 \mathrm{~nm}$ wavelength. Thus, BGE pH was selected as 8.5 for subsequent studies.

The effect of applied voltage was examined in the range $10 \mathrm{kV}$ to $20 \mathrm{kV}$ using three replicate injections at each voltage. As the applied voltage was increased, the migration time was shortened and the peak area was increased, but the resolution was decreased. The applied voltage of $16 \mathrm{kV}$ was selected for the experiment with satisfying sensitivity and migration time.

3.3. Linearity and $L O D$. The curves were prepared by adding different concentrations of NOR and CIP in drug-free samples. Linear calibration curves of NOR and CIP in chicken meat were obtained at the concentration range of $0.10 \mu \mathrm{g} \mathrm{g}^{-1}$ to $500 \mu \mathrm{g} \mathrm{g}^{-1}$. The correlation coefficients were 0.9994 and 0.9986 , respectively. The LODs (signal-to-noise ratio of 3, $\mathrm{S} / \mathrm{N}=3$ ) of NOR and CIP were 0.04 and $0.03 \mu \mathrm{gg}^{-1}$, and the LODs (signal-to-noise ratio of $3, \mathrm{~S} / \mathrm{N}=10$ ) of NOR and CIP were 0.12 and $0.10 \mu \mathrm{gg}^{-1}$, respectively. The MRLs in meat established by European community for NOR and CIP are $100 \mu \mathrm{g} \mathrm{kg}^{-1}$ [8]; therefore the method is sensitive enough to be applied in chicken meat.

3.4. Real Sample Analysis. Different spiked concentrations $\left(0.50,2.00\right.$, and $\left.10.00 \mu \mathrm{gg}^{-1}\right)$ of NOR and CIP in drugfree chicken meat were adopted to examine the recovery and precision of the method in analyzing NOR and CIP. The results of intraday and interday precision and accuracy experiments are summarized in Table 2. In our experiments, the precision of NOR was usually $<5.8 \%$ at the medium, and higher concentration levels and did not exceed $6.8 \%$ at the low concentration level. Accuracy values always ranged between $86.4 \%$ and $103.2 \%$. The precision of CIP was $<4.9 \%$ at the medium and high concentration levels and did not exceed $6.2 \%$ at the low concentration level. Accuracy values always 


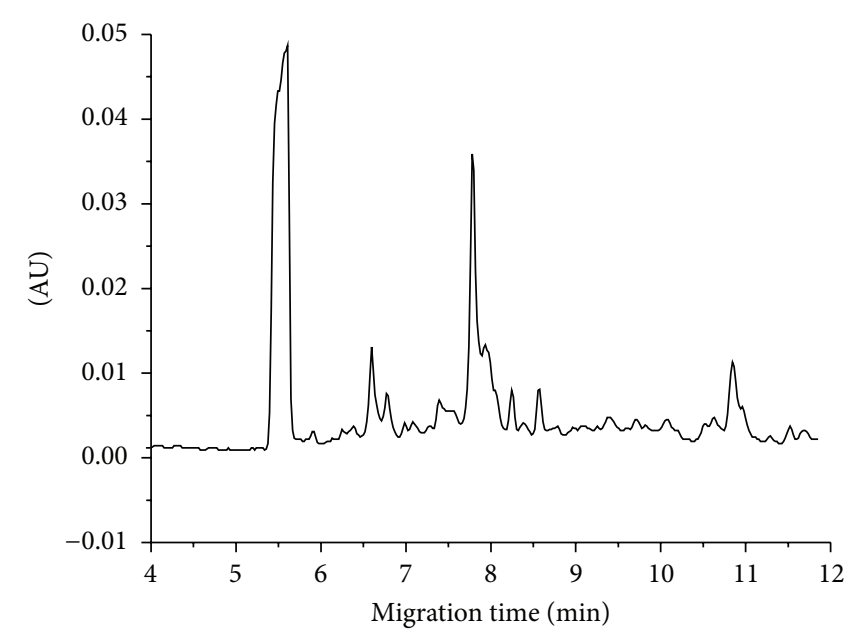

(a)

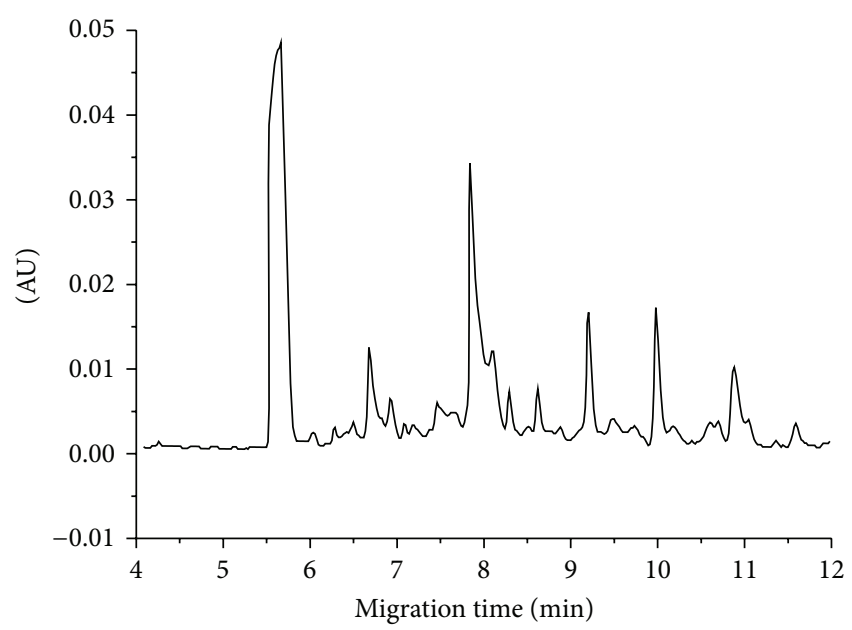

(b)

FIGURE 3: Electropherograms obtained from (a) a chicken meat sample and (b) the sample spiked with NOR and CIP at $10.00 \mu \mathrm{g} \mathrm{g}^{-1}$. Conditions: separation buffer, $40 \mathrm{mmol} \mathrm{L}^{-1}$ borate buffer solution $(\mathrm{pH} 8.5)$, separation voltage $10 \mathrm{kV}$; detection at $280 \mathrm{~nm}$.

TABLE 2: Determination of NOR and CIP in chicken meat.

\begin{tabular}{lcccc}
\hline & $\begin{array}{c}\text { Added } \\
\left(\mu \mathrm{gg}^{-1}\right)\end{array}$ & $\begin{array}{c}\text { Found } \\
\left(\mu \mathrm{g} \mathrm{g}^{-1}\right)\end{array}$ & $\begin{array}{c}\text { Recovery } \\
(\%)\end{array}$ & $\begin{array}{c}\text { RSD } \\
(\%)\end{array}$ \\
\hline NOR & & & & \\
& 0.50 & $0.47 \pm 0.025$ & 94.0 & 5.4 \\
Intraday $(n=9)$ & 2.00 & $1.86 \pm 0.085$ & 92.8 & 4.6 \\
& 10.00 & $10.32 \pm 0.506$ & 103.2 & 4.9 \\
& 0.50 & $0.43 \pm 0.029$ & 86.4 & 6.8 \\
Interday $(n=9)$ & 2.00 & $1.95 \pm 0.101$ & 97.5 & 5.2 \\
& 10.00 & $9.58 \pm 0.556$ & 95.8 & 5.8 \\
CIP & & & & \\
& 0.50 & $0.47 \pm 0.023$ & 94.2 & 4.8 \\
Intraday $(n=9)$ & 2.00 & $1.91 \pm 0.067$ & 95.4 & 3.5 \\
& 10.00 & $10.56 \pm 0.401$ & 105.6 & 3.8 \\
& 0.50 & $0.45 \pm 0.028$ & 90.1 & 6.2 \\
Interday $(n=9)$ & 2.00 & $2.09 \pm 0.100$ & 104.5 & 4.8 \\
& 10.00 & $9.84 \pm 0.482$ & 98.4 & 4.9 \\
\hline
\end{tabular}

ranged between $90.1 \%$ and $105.6 \%$. The recoveries and precision of the method were better than those from the ELISA method [21]. Figure 3 shows the typical electropherograms obtained from drug-free and spiked chicken meat samples.

\section{Conclusions}

This study describes a methodology for the determination and quantification of NOR and CIP in chicken meat by CZE using a preconcentration step of MSPD. This well-controlled method has generated high-quality data with acceptable levels of precision, accuracy, working range, and LOD.

\section{Conflict of Interests}

The authors declare that there is no conflict of interests regarding the publication of this paper.

\section{Acknowledgments}

The authors acknowledge the financial support from the Key Project of Science and Technology Department of Hebei province (11230909D-3), International Science and Technology Cooperation Project of China (2011DFA32930), Shenzhen Technology Research and Development Foundation Program (JSGG20130624152620659), and 2014 Annual Bidding Project of Rule of Virtue and Law Collaborative Innovation Center in Social Management of Hebei University of Economic and Business (2014ZBKT12).

\section{References}

[1] F. W. Fraunfelder and F. T. Fraunfelder, "Diplopia and Fluoroquinolones," Ophthalmology, vol. 116, no. 9, pp. 1814-1817, 2009.

[2] M. Yamada, H. Mochizuki, K. Yamada, M. Kawai, and Y. Mashima, "Aqueous humor levels of topically applied levofloxacin, norfloxacin, and lomefloxacin in the same human eyes," Journal of Cataract and Refractive Surgery, vol. 29, no. 9, pp. 1771-1775, 2003.

[3] C. González-Chomón, M. E. M. Braga, H. C. Sousa, A. Concheiro, and C. Alvarez-Lorenzo, "Antifouling foldable acrylic IOLs loaded with norfloxacin by aqueous soaking and by supercritical carbon dioxide technology," European Journal of Pharmaceutics and Biopharmaceutics, vol. 82, no. 2, pp. 383-291, 2012.

[4] S. P. Quesada, J. A. R. Paschoal, and F. G. R. Reyes, "Considerations on the aquaculture development and on the use of veterinary drugs," Journal of Food Science, vol. 78, no. 9, pp. 13211333, 2013.

[5] R. Xiao, Z. He, D. Diaz-Rivera, G. Y. Pee, and L. K. Weavers, "Sonochemical degradation of ciprofloxacin and ibuprofen 
in the presence of matrix organic compounds," Ultrason Sonochem, vol. 21, no. 1, pp. 428-435, 2014.

[6] K. C. Mountzouris, V. Paraskevas, P. Tsirtsikos et al., "Assessment of a phytogenic feed additive effect on broiler growth performance, nutrient digestibility and caecal microflora composition," Animal Feed Science and Technology, vol. 168, no. 3-4, pp. 223-231, 2011.

[7] H. M. Tamim, K. M. Musallam, H. M. A. Kadri, J.-F. Boivin, and J.-P. Collet, "Antibiotic use and risk of gynecological cancer," European Journal of Obstetrics Gynecology and Reproductive Biology, vol. 159, no. 2, pp. 388-393, 2011.

[8] A.-C. Huet, C. Charlier, S. A. Tittlemier, G. Singh, S. Benrejeb, and P. Delahaut, "Simultaneous determination of (fluoro)quinolone antibiotics in kidney, marine products, eggs, and muscle by enzyme-linked immunosorbent assay (ELISA)," Journal of Agricultural and Food Chemistry, vol. 54, no. 8, pp. 2822-2827, 2006.

[9] R. Nageswara Rao and V. Nagaraju, "Separation and determination of synthetic impurities of norfloxacin by reversedphase high performance liquid chromatography," Journal of Pharmaceutical and Biomedical Analysis, vol. 34, no. 5, pp.10491056, 2004.

[10] X. Yu and J. Bao, "Determination of norfloxacin using gold nanoparticles catalyzed cerium(IV)-sodium sulfite chemiluminescence," Journal of Luminescence, vol. 129, no. 9, pp. 973-978, 2009.

[11] A. A. J. Torriero, E. Salinas, J. Raba, and J. J. Silber, "Sensitive determination of ciprofloxacin and norfloxacin in biological fluids using an enzymatic rotating biosensor," Biosensors and Bioelectronics, vol. 22, no. 1, pp. 109-115, 2006.

[12] I. A. Darwish, M. A. Sultan, and H. A. Al-Arfaj, "Novel selective kinetic spectrophotometric method for determination of norfloxacin in its pharmaceutical formulations," Talanta, vol. 78, no. 4-5, pp. 1383-1388, 2009.

[13] A. Alnajjar, A. M. Idris, and H. H. AbuSeada, "Development of a stability-indicating capillary electrophoresis method for norfloxacin and its inactive decarboxylated degradant," Microchemical Journal, vol. 87, no. 1, pp. 35-40, 2007.

[14] Y. M. Liu, J. T. Cao, and H. Wang, "Capillary electrophoresis with electrochemiluminescence detection for the analysis of quinolone drugs and pharmacokinetics study," Chinese Chemical Letters, vol. 19, no. 8, pp. 962-964, 2008.

[15] Q. Xia, Y. Yang, and M. Liu, "Aluminium sensitized spectrofluorimetric determination of fluoroquinolones in milk samples coupled with salting-out assisted liquid-liquid ultrasonic extraction," Spectrochimica Acta A, vol. 96, pp. 358-364, 2012.

[16] H.-B. Lee, T. E. Peart, and M. L. Svoboda, "Determination of ofloxacin, norfloxacin, and ciprofloxacin in sewage by selective solid-phase extraction, liquid chromatography with fluorescence detection, and liquid chromatography-tandem mass spectrometry," Journal of Chromatography A, vol. 1139, no. 1, pp. 45-52, 2007.

[17] A. L. Capriotti, C. Cavaliere, A. Laganà, S. Piovesana, and R. Samperi, "Recent trends in matrix solid-phase dispersion," Trac-Trend Analytical Chemistry, vol. 43, pp. 53-66, 2013.

[18] Y. Hong and L. Chen, "Extraction of quercetin from Herba Lysimachiae by molecularly imprinted-matrix solid phase dispersion," Journal of Chromatography B, vol. 941, pp. 38-44, 2013.

[19] J. Cheng, M. Liu, Y. Yu et al., "Determination of pyrethroids in porcine tissues by matrix solid-phase dispersion extraction and high-performance liquid chromatography," Meat Science, vol. 82, no. 4, pp. 407-412, 2009.
[20] M. T. Montero, D. Saiz, R. Sitges, J. L. Vázquez, and J. H. Borrell, "Influence of physicochemical properties of fluoroquinolones on encapsulation efficiency in liposomes," International Journal of Pharmaceutics, vol. 138, pp. 113-120, 1996.

[21] J. Jiang, H. Zhang, J. Liu, J. Li, and Z. Wang, "Development and optimization of an indirect competitive ELISA for detection of norfloxacin residue in chicken liver," Procedia Environmental Sciences, vol. 8, pp. 128-133, 2011. 

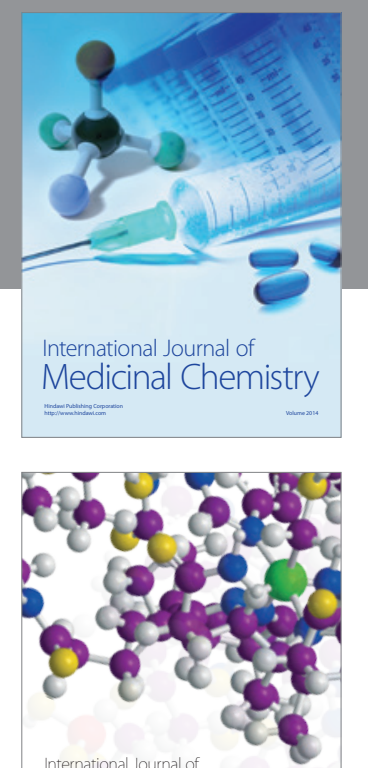

\section{Carbohydrate} Chemistry

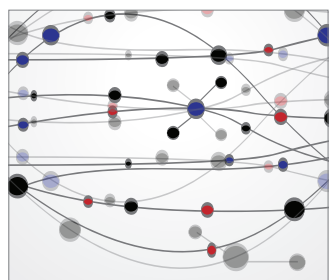

The Scientific World Journal
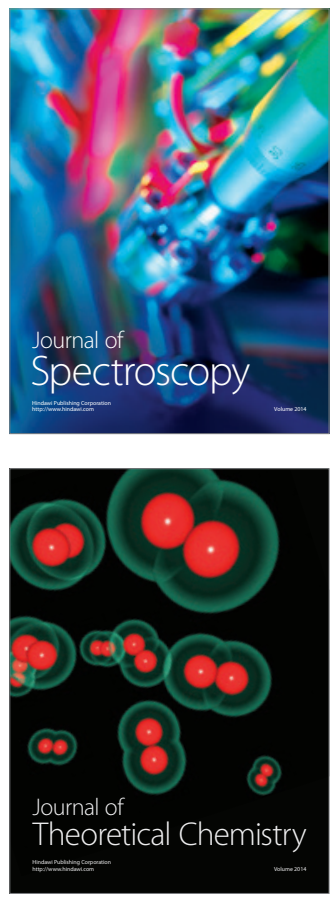
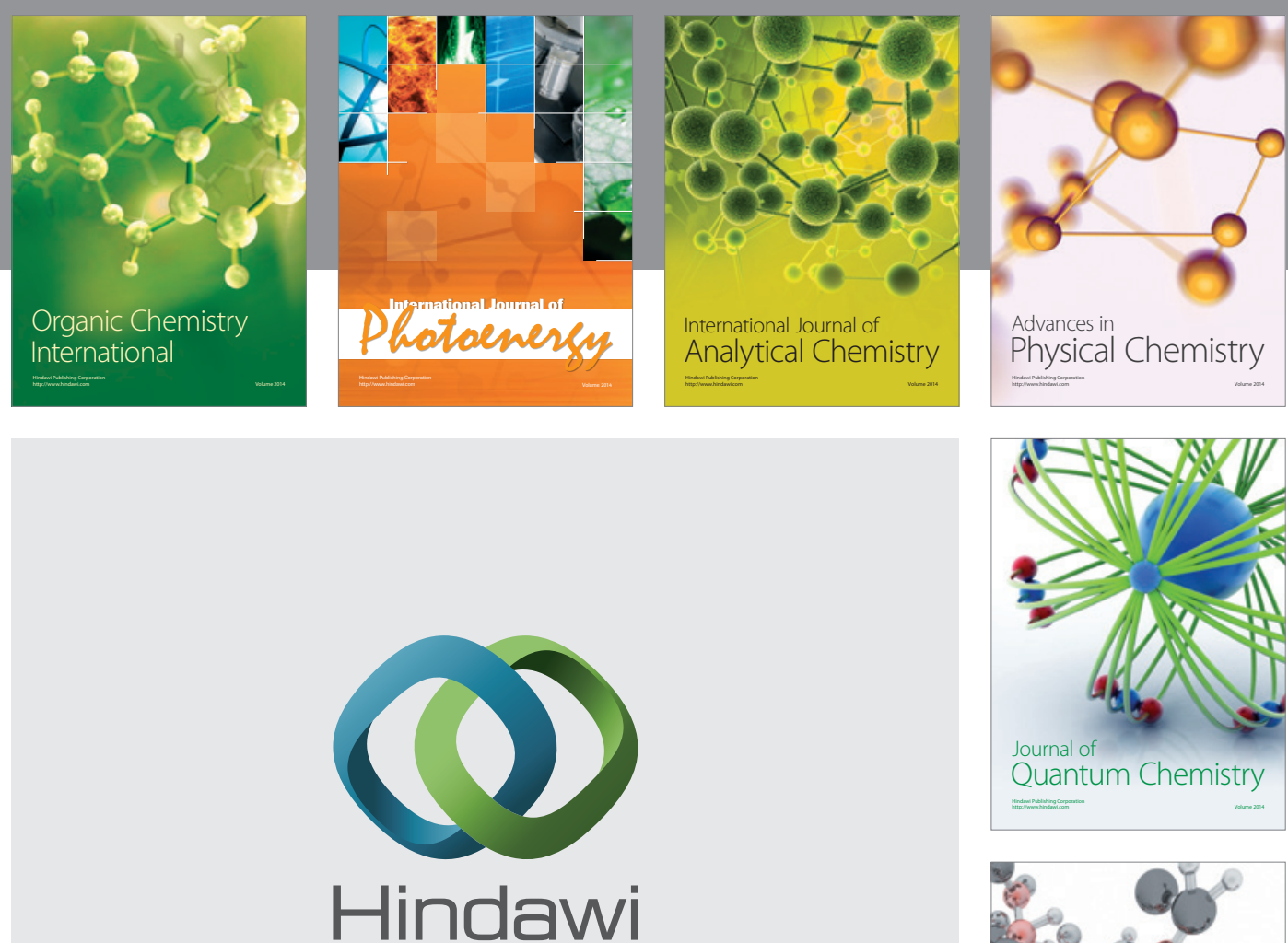

Submit your manuscripts at

http://www.hindawi.com

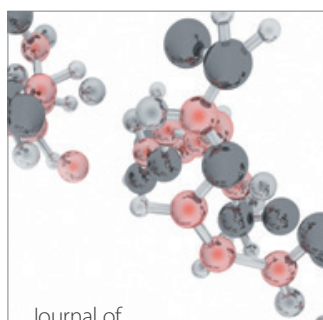

Analytical Methods

in Chemistry

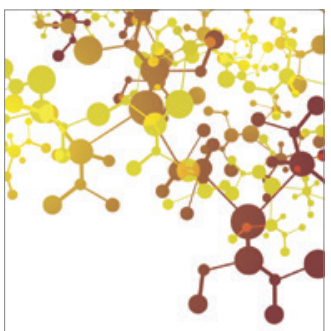

Journal of

Applied Chemistry

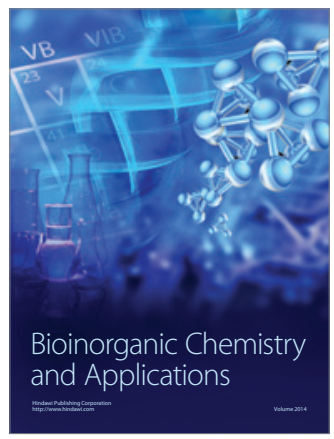

Inorganic Chemistry
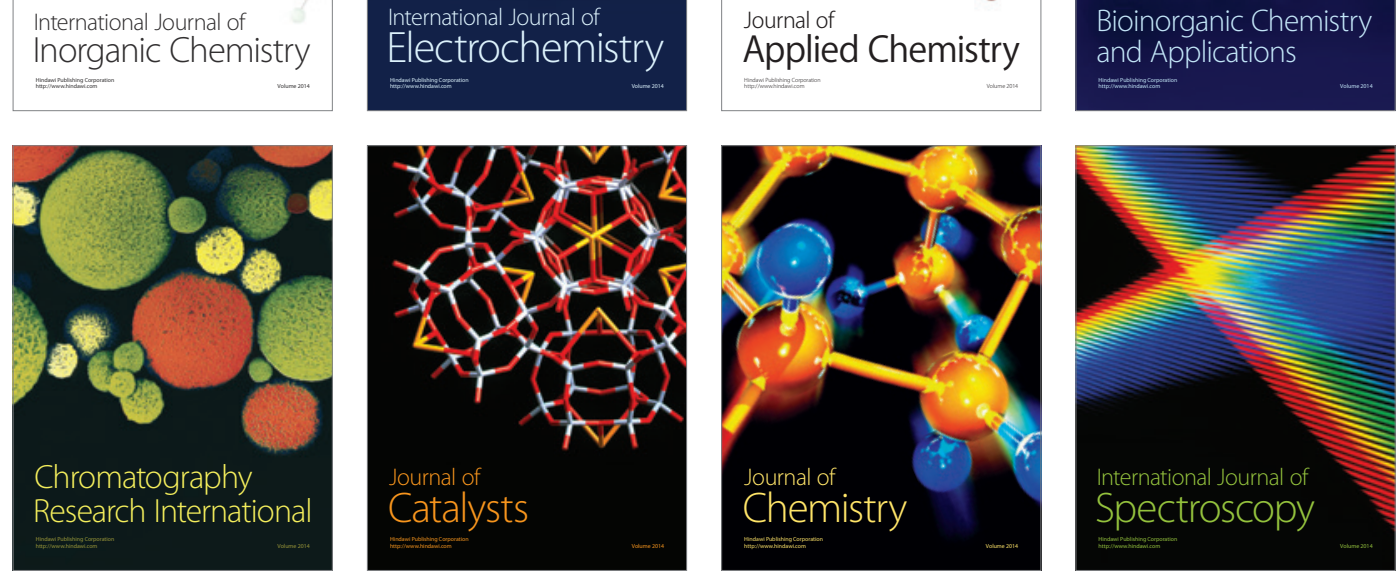